\title{
Centralisation of procurement and supply chain management in the English NHS: some governance and compliance challenges

\author{
Dr Albert Sanchez-Graells*
}

Centre for Health, Law, and Society, University of Bristol Law School

\begin{abstract}
This paper provides a critical analysis of the new operating model for NHS procurement that is being implemented in 2018/2019 (the NOM). The government expects NOM to generate significant savings through centralised procurement and strategic supply chain management, which would then be dedicated to frontline NHS healthcare services through newly devised 'sustainability and transformation plans' (STPs). The paper stresses that the NOM rests on a complex network of contracts resulting in a layer of contractualised governance that obscures its architecture and decision-making processes. It maps the changes that the NOM introduces in the operation and governance of the NHS supply chain and identifies key challenges in ensuring that the NOM is subjected to adequate oversight and accountability mechanisms, in particular from the perspective of public procurement and competition law. The paper advocates for the location of all NOM relationships on the NHS Business Services Authority, especially to facilitate judicial review.
\end{abstract}

Keywords: NHS; procurement; centralisation; supply chain; efficiency; savings; service delivery; governance.

JEL codes: H57; H75; I18; K23; K49.

\section{Introduction}

A ttaining public health goals and satisfying a population's need for healthcare services Arequires a complex mix of governance and delivery structures. States have a wide range of choices in the design of healthcare governance and delivery systems along a continuum that goes from pure in-house public service management, delivery and governance, to purely privatised delivery, outsourced management and light-touch public oversight of healthcare services. In almost any of these models - with the only exception being completely self-sufficient systems (which remain a theoretical possibility) - the delivery of public services requires the acquisition of goods and equipment from the market through public procurement. In other words, states do not tend to manufacture the large and diverse

* Reader in Economic Law and Member of the Centre for Health, Law, and Society at the University of Bristol Law School; Former Member of the European Commission Stakeholder Expert Group on Public Procurement (2015-2018). All opinions are my own and do not reflect those of the institutions to which I am affiliated. I am grateful to Catherine Wolfenden (Osborne Clarke), Dr Jule Mulder, Professor Keith Syrett, Professor John Coggon and two anonymous reviewers for comments to previous drafts. The standard disclaimer applies. Further comments welcome: a.sanchez-graells@bristol.ac.uk.

Note: all websites last accessed on 4 December 2018. 
volumes of healthcare equipment and consumables (such as diagnostic equipment, test chemicals or surgical materials, but also simpler products, such as hospital food) that they require, but rather buy them from the market, and generally from private companies. ${ }^{1}$ In that regard, states also have policy choices between, for example, central procurement by a public authority, decentralised procurement by hospitals, either of those types of procurement by private bodies, or an entirely private contracting system subject to public (i.e. statutory) obligations.

From a governance perspective, each of these models creates a different balance of risks and benefits, and mixed systems (which are by and large the majority in developed economies) are exposed to governance needs and risks that not only involve the public authorities, bodies and institutions tasked with the delivery of healthcare services, but also private providers. As evidenced in recent UK scandals - such as Carillion, Capita, Southern Cross or $\mathrm{G}_{4} \mathrm{~S}^{2}$ - governance vulnerabilities derived from private involvement are increasingly seen as a major flaw of mixed systems. Contractualised and privatised systems are also exposed to increased litigation risks, in particular concerning the tendering of new contracts - as also evidenced in recent UK experiences, such as the DHL challenge to the implementation of the new healthcare procurement system discussed in this paper. ${ }^{3}$ All of this is prompting a reconsideration of the system architecture for the delivery of public services - both in healthcare and in other areas. More generally, the choice between different system design options is clearly influenced by the underlying economic model of a given state's constitutional settlement, social preferences, capability and funding constraints, and a number of other factors - amongst which free trade agreements and liberalisation efforts are gaining prominence. Economic efficiency in the expenditure of public funds for the provision of healthcare services is an increasingly important consideration or driver in the (re)design of healthcare systems. This has become particularly acute in the post-2008 financial crisis austerity-driven world.

1 This may be particularly obvious (and sometimes problematic) concerning medicines and other pharmaceutical products. However, these are not covered by the discussion in this paper, as their acquisition is subjected to a separate set of statutory and contractual mechanisms. For background, see NHS Specialist Pharmacy Service, An Overview of NHS Procurement of Medicines and Pharmaceutical Products and Services for Acute Care in the United Kingdom (22 October 2018) <www.sps.nhs.uk/articles/an-overview-of-nhs-procurement-ofmedicines-and-pharmaceutical-products-and-services-for-acute-care-in-the-united-kingdom $>$.

2 Carillion may have been the most prominent of recent scandals, as widely evidenced in the report by the Business, Energy and Industrial Strategy and Work and Pensions Committees, Carillion (HC 2017-19 769). However, similar vulnerabilities of overly reliant privatised and contractualised systems are also evident in the difficulties resulting from Capita's mismanagement of primary care support services; see NAO, NHS England's Management of the Primary Care Support Services Contract with Capita (HC 2017-19 632). The evidence piles up in other examples concerning Southern Cross's mismanagement of nursing and care homes - see e.g. Care Quality Commission, Report on the Stability of the Care Market and Market Oversight in England (February 2014) <www.cqc.org.uk/sites/default/files/201402-market-stability-report.pdf> - or the repeated failings of G4S in the area of security services and prison management, which most recently required a governmental stepin: see Jessica Elgot, 'MoJ Seizes Control of Birmingham Prison from G4S' The Guardian (London, 20 August 2018) <www.theguardian.com/business/2018/aug/20/moj-seizes-control-of-birmingham-prison-from$\mathrm{g} 4 \mathrm{~s}>$.

3 This is discussed in more detail below. Suffice it to indicate here that, as the incumbent provider, DHL challenged the award of a logistics contract to new entrant Unipart, and this resulted in significant delays in the implementation of the new operating model for NHS procurement. See DHL Supply Chain Ltd v Secretary of State for Health and Social Care [2018] EWHC 2213 (TCC) (17 August 2018) and Nick Carding, 'DHSC awards $f_{7} 730 \mathrm{~m}$ NHS Logistics Contract Following High Court Victory' (Health Service Journal, 5 September 2018) <www.hsj.co.uk/finance-and-efficiency/dhsc-awards-730m-nhs-logistics-contract-following-highcourt-victory/7023285.article>. 
Indeed, the celebrations of the 70th anniversary of the English NHS arrived in 2018 after a decade of funding cuts and austerity policies, coupled with constant experimentation in the re-regulation of the market-based governance mechanisms that had been employed since the creation of the 'NHS internal market' in the 1990s. The most recent effort to re-regulate the governance of the NHS concentrates on the implementation of rather ambitious sustainability and transformation plans (STPs), which could be seen as the first step towards putting an end to the NHS internal market and reconstructing mechanisms of public governance and oversight, albeit through the conduit of newly created 'integrated care systems'. ${ }^{4}$ The purpose of this paper is not to assess the STPs, but rather to concentrate on flanking policies aimed at liberating public funds already dedicated to healthcare services that can then fund the ambitions of the STPs (or whichever NHS re-regulation strategy replaces them in the future). In particular, this paper concentrates on recent efforts to achieve savings in the expenditure of NHS funds in the acquisition of the medical equipment, consumables and services required for the provision of healthcare services. As one of the biggest publicly funded healthcare systems in the world, the NHS has a non-pay expenditure of approximately $£ 27$ billion a year, of which nearly $f_{6} 6$ billion is spent on goods (everyday hospital consumables, highcost devices, capital equipment and common goods). Achieving savings, even relatively small ones, on such a large volume of expenditure could liberate significant funds that could be reallocated to frontline delivery.

The most recent wave of efficiency-seeking re-regulation of NHS procurement through the so-called Procurement Transformation Plan (PTP), and the resulting New Operating Model (NOM), pivots around the exercise of public buying power through aggregation of demand and, in particular, through the centralisation of procurement and the streamlining of supply chain management. Interestingly, these strategies are channelled through entirely privatised (or contractualised) structures that take the procurement function away from NHS trusts and grants significant decision-making powers to non-statutory bodies and private entities - which creates a high level of opacity of both the architecture and the governance of NHS procurement under the NOM. While theoretically capable of delivering significant cost efficiencies, these reforms also create significant implementation and governance challenges. This could shield important decision-making processes from adequate mechanisms of control, in particular through judicial review, and result in a circumvention or watering-down of significant constraints, such as those derived from public procurement and competition law.

After providing an overview of the recent reforms of the NHS market-based governance through the STPs to contextualise the discussion, this paper critically analyses how the NHS is trying to take advantage of centralised procurement and supply chain management strategies through the NOM; and how this strategy triggers governance and legal compliance challenges, in particular from the perspective of public procurement and competition law.

\section{Abandoning the 'NHS internal market'? Recent NHS governance reforms}

In England, economic efficiency, value for money or savings in healthcare expenditure (however one wants to label it) has been the main driving factor behind the constant transformation of the governance and public/private boundaries of the NHS over the last three decades. These reforms have sought to rely on market-based governance

4 Note that these were initially labelled as 'accountable care systems', and they may appear as such in NHS documents cited in this paper. For more details, see NHS, 'Integrated Care Systems' (undated) $<$ www.england.nhs.uk/integratedcare/integrated-care-systems $>$. 
structures to unlock economic efficiency and high-powered incentives for the generation of ever-increasing savings in healthcare expenditure. This has taken place in different waves, starting with the creation of the 'NHS internal market' on 1 April 1991.5 Indeed, since the 1990s, in England, the activities of the NHS have been characterised by a rather distinctive purchaser-provider split whereby some branches of the NHS act as purchasers or commissioners of healthcare services (currently, clinical commissioning groups, or CCGs), while other branches of the NHS (trusts and foundation trusts) act as providers of healthcare services and compete with private providers in some markets. The commissioning of services within the NHS internal market is subject to special rules that seek to further the patients' interest. ${ }^{6}$ The activities of these entities in such quasi-markets for healthcare services are overseen by NHS Improvement as sector regulator.

The purchaser-provider split policy was introduced with the aim of creating an 'NHS internal market' to generate competition-based incentives for the improvement of service delivery and cost management. ${ }^{7}$ However, the system has been permanently evolving (or in a 'continuous revolution'), ${ }^{8}$ and this has both created increased scope for publicprivate competition ${ }^{9}$ and notable difficulties in keeping pace with the successive waves of NHS re-regulation. Most recently, government policy has shifted towards a roll-back or undoing of the NHS internal market. ${ }^{10}$ Since the adoption in 2014 of the Five Years Forward View for the NHS in England, ${ }^{11}$ the system has been progressively reoriented. Current reforms are geared towards experimentation with the so-called STPs, which aim to suppress the purchaser-provider split and bring about integrated funding and delivery for a given geographical population through integrated care systems. ${ }^{12}$

However, important elements of the STP strategy are still unclear and there are open questions concerning its feasibility and/or desirability. ${ }^{13}$ The National Audit Office (NAO) has already warned that the 'partnerships' effectiveness varies and their tight financial positions make it difficult for them to shift focus from short-term day-to-day pressures to delivering transformation of services', which led it to estimate that the

5 Ray Robinson, 'The Impact of the NHS Reforms 1991-1995: A Review of Research Evidence' (1996) 18(3) Journal of Public Health Medicine 337.

6 For discussion, see Albert Sanchez-Graells, 'New Rules for Health Care Procurement in the UK. A Critical Assessment from the Perspective of EU Economic Law' (2015) 24(1) Public Procurement Law Review 16.

7 For discussion, see Barbara Ann Allen, Elizabeth Wade and Helen Dickinson, 'Bridging the Divide Commercial Procurement and Supply Chain Management: Are There Lessons for Health Care Commissioning in England?' (2009) 9 Journal of Public Procurement 505.

8 Alan Maynard, in 'Should the NHS Abolish the Purchaser-Provider Split?' (British Medical Journal, 12 July 2016) <https://doi.org/10.1136/bmj.i3825>.

9 Okeoghene Odudu, 'Competition Law and the National Health Service' (Competition Bulletin, 8 October 2012) <https://competitionbulletin.com/2012/10/08/competition-law-and-the-national-health-service>; David J Hunter, 'Does the NHS still Reside in a Grey Area for EU Competition Law?' (UKiCE blog, 6 April 2016) $<$ http://ukandeu.ac.uk/does-the-nhs-still-reside-in-a-grey-area-for-eu-competition-law $>$.

10 'Is this the End of the NHS's Internal Market?' (Economist, 2 November 2017) <www.economist.com/britain/2017/11/02/is-this-the-end-of-the-nhss-internal-market>.

11 NHS England, 'NHS Five Year Forward View' (22 October 2014) <www.england.nhs.uk/publication/nhsfive-year-forward-view $>$.

12 This has not changed after the adoption of the NHS, see <www.longtermplan.nhs.uk $>$. For discussion on current STP implementation, see Public Accounts Committee, Oral Evidence: Integrated Health and Social Care (HC 2016-17 959) Q93. For discussion, see Allyson Pollock and Peter Roderick, 'Why We should be Concerned about Accountable Care Organisations in England's NHS' (British Medical Journal, 30 January 2018) <https://doi.org/10.1136/bmj.k343>.

13 David Hare, 'The End of the Purchaser/Provider Split?' (NHS Confederation, 14 March 2017) $<$ www.nhsconfed.org/blog/2017/03/the-end-of-the-purchaser-provider-split>. 
implementation of STPs' plans would require $£ 10$ billion of extra capital. ${ }^{14}$ This issue had significant salience in the 2017 general election, with both the Conservative ${ }^{15}$ and the Labour $^{16}$ manifestos pledging more funding for the NHS and alluding to a change of system. Despite renewed pledges for additional NHS funding made by the current Conservative government on the occasion of the NHS's 70th anniversary ${ }^{17}-$ and even if there was a change of government and Labour implemented its own view for the future of the NHS ${ }^{18}$ - the transformation or abandonment of the NHS internal market will require further additional funding.

\section{Seeking savings to support the transformation: NHS procurement in the spotlight}

At this juncture, it is worth stressing that, regardless of the way in which the NHS is internally managed - i.e. with or without the NHS internal market - the provision of public healthcare services requires and will continue to require the acquisition of supplies and services from the market. That is, even in the absence of the NHS internal market, the provision of healthcare services by the NHS will continue to require an interaction with the (broader/external) market through the acquisition of goods and services. Indeed, NHS providers do not produce all equipment, consumables and services needed for the provision of healthcare to the general population and they will continue buying them from the market in the future. Therefore, 'doing more with less', or seeking savings in NHS procurement seems one way (or the only way, if further savings in workforce are no longer sought $)^{19}$ of freeing up additional funds for the transformation of the NHS without (significantly) increasing overall healthcare expenditure. Put simply, seeking 'more bang for your pound' becomes one (or the) main goal in NHS procurement governance.

This realisation materialised in a particularly acute manner in 2012, when the Department of Health and Social Care identified scope for the NHS to save at least $f_{1} 1.2$ billion through improved NHS procurement ${ }^{20}$ - which doubled the previous estimate of $£, 500$ million by the $\mathrm{NAO},{ }^{21}$ and would have required NHS trusts to find over $f, 1.5$ billion of procurement efficiencies over the three years following the 2013 NHS England

14 NAO, Sustainability and Transformation in the NHS (HC 2017-19 719).

15 Conservative Unionist Party Manifesto 2017 <https://s3.eu-west-2.amazonaws.com/conservative-partymanifestos/Forward+Together+-+Our+Plan+for $+\mathrm{a}+$ Stronger+Britain + and $+\mathrm{a}+$ More+Prosperous....pdf $>$. The relevant pledge was to 'consult and make the necessary legislative changes. This includes the NHS's own internal market, which can fail to act in the interests of patients and creates costly bureaucracy. So we will review [its] operation ... and, in time for ... the 2018 financial year, we will make non-legislative changes to remove barriers to the integration of care' (at 67).

16 Labour Party Manifesto 2017 <https://labour.org.uk/wp-content/uploads/2017/10/labour-manifesto2017.pdf>. The relevant pledge was to 'reverse privatisation of our NHS and return our health service into expert public control [including the] repeal [of] the Health and Social Care Act . . and [making] the NHS the preferred provider' (69).

17 Denis Campbell, 'Theresa May Pledges to Accelerate NHS Long-term Funding Plan’ The Guardian (London, 27 March 2018) <www.theguardian.com/society/2018/mar/27/theresa-may-pledges-to-accelerate-nhs-longterm-funding-plan>.

18 Jessica Elgot, 'Labour Consults on Plan for Major NHS Restructuring' The Guardian (London, 2 June 2018) <www.theguardian.com/society/2018/jun/02/labour-consults-on-plan-for-major-nhs-restructuring>.

19 Haroon Siddique, 'NHS to Receive $f 487 \mathrm{~m}$ Technology Boost. Matt Hancock Lists Top Three Priorities as Tech, Workforce and Illness Prevention' The Guardian (London, 20 July 2018) <www.theguardian.com/society/2018/jul/20/nhs-to-receive-487m-technology-boost-matt-hancock>.

20 Department of Health and Social Care, 'NHS Procurement: Raising our Game' (28 May 2012) $<$ www.gov.uk/government/publications/nhs-procurement-raising-our-game>.

21 NAO, The Procurement of Consumables by NHS Acute and Foundation Trusts (HC 2010-11 705). 
Procurement Development Programme. ${ }^{22}$ Even if of a smaller magnitude, the potential for significant savings in NHS procurement was later confirmed in 2016 by the Carter Review, ${ }^{23}$ which estimated potential NHS procurement savings resulting from reduced variation across NHS trusts of at least $\mathcal{f} 700$ million.

All of these studies and estimates pointed at the potential economic savings derived from a more homogeneous, streamlined selection of supplies and suppliers to the NHS (i.e. reduced variation) and a more strategic exercise of NHS buying and negotiating power vis-à-vis its main suppliers (which was expected to lead to cost reductions and/or increased quality, depending on the relevant goods and services). On the whole, the realisation that there were (and still are) efficiencies to be had in NHS procurement resulted in the launch of the PTP and its current goal for the NHS to deliver $£, 700$ million in savings from improving procurement by the end of the financial year 2020/2021, ${ }^{24}$ reaching $f^{2.4}$ billion savings delivered by the end of $2022 / 2023,{ }^{25}$ and for the NOM to result in end-state annual savings of $f^{6} 615$ million in real terms from 2022/2023 onwards. ${ }^{26}$ These estimates and expectations of savings need to be taken with appropriate caution, as other complex NHS transformation programmes have resulted in significant problems that limited or wiped out any expected efficiencies. ${ }^{27}$ Government assessments in this area have often focused on the demand-side and assumed that NHS bargaining power is infinite, so that it is just a matter of applying it better. However, it is clear that (at least) in some areas there will also be supplier bargaining power, and efforts by the NHS to achieve lower prices (on average) will be resisted by suppliers. Thus, these estimates and projections need to be taken with a pinch of salt. However, the purpose of this paper is not to challenge these savings estimates, but rather to critically assess the legality and governability of the structures that are being put in place to unlock them.

It is thus worth zooming in on the fact that the Department of Health and Social Care expects the NHS to achieve these savings through procurement centralisation and a more strategic supply chain management. ${ }^{28}$ This is not a new goal, but rather a revamp of a strategy that already underpinned the creation in 2005 of the NHS Business Services Authority - an

22 Department of Health/NHS England, 'Better Procurement, Better Value, Better Care: A Procurement Development Programme for the NHS' (5 August 2013) <www.gov.uk/government/publications/improving-procurement-in-the-nhs>.

23 Lord Carter of Coles, Independent Report for the Department of Health on Operational Productivity and Performance in English NHS Acute Hospitals: Unwarranted Variations (February 2016) <www.gov.uk/government/publications/productivity-in-nhs-hospitals>. See also Will Green, 'Procurement Can Deliver $\ell^{1}$ billion of NHS Savings a Year, says Lord Carter' (Supply Management, 11 June 2015) <www.cips.org/supply-management/news/2015/june/procurement-can-deliver-1-billion-of-nhs-savings-ayear-says-lord-carter>.

24 This is a rather ambitious goal, the feasibility of which has been doubted. See e.g. Richard McIntosh, 'The Carter Report - Can NHS Procurement Transformation be Accelerated?' (Health Service Journal, 7 March 2016) <www.hsj.co.uk/comment/the-carter-report--can-nhs-procurement-transformation-beaccelerated/7003033.article>.

25 NHS Supply Chain, 'SCCL News: Supply Chain Coordination Limited of NHS Supply Chain' (2018) $<$ www.supplychain.nhs.uk/sccl>.

26 NHS Procurement Transformation Programme, 'Future Operating Model (FOM) Handbook' (Issue 1: October 2017) (hereinafter, the 'FOM Handbook') <www.supplychain.nhs.uk/icc/ /media/Files/News/FOM_HANDBOOK\%20Oct\%202017.ashx> .

27 See NAO (n 2).

28 For an overview of the evolution of NHS procurement structures up to 2015, see Joe Sanderson et al, 'Towards a Framework for Enhancing Procurement and Supply Chain Management Practice in the NHS: Lessons for Managers and Clinicians from a Synthesis of the Theoretical and Empirical Literature' (2015) 18 Health Services and Delivery Research 3 <www.ncbi.nlm.nih.gov/books/NBK286079>. 
executive non-departmental public body (NDPB) of the Department of Health and Social Care that provides some support services to the NHS in England and Wales. ${ }^{29} \mathrm{At}$ the same time, there was a reorganisation of the NHS Logistics Authority and parts of the NHS Purchasing and Supply Agency (PASA), which became part of what is known as the NHS Supply Chain. ${ }^{30}$ NHS Supply Chain is not a separate entity or body, but rather a logistics management unit under the umbrella of the NHS Business Services Authority, currently operated by the private company DHL (DHL Supply Chain Ltd) under a longterm outsourcing contract. NHS Supply Chain does not have separate legal personality, but is rather a front or holding place for the underlying contract for logistical and other services. However, this is not necessarily observable in all or most interactions with third parties, as NHS Supply Chain externally presents itself as an 'organisation'. ${ }^{31}$ Figure 1 provides a schematic representation of the relationships between these entities.

Figure 1: NHS supply chain governance

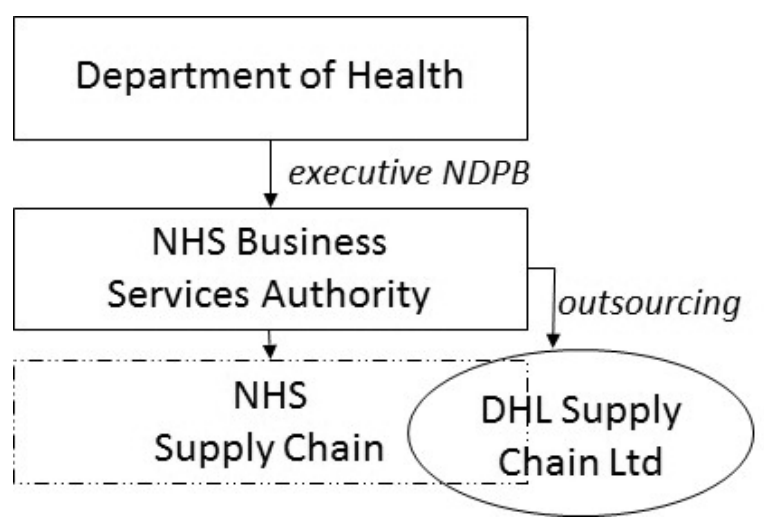

Source: own elaboration

NHS Supply Chain provides centralised procurement services to the NHS. It manages framework contracts and other contractual mechanisms that allow direct access to suppliers by NHS procurers. NHS Supply Chain is thus a procurement intermediary for NHS trusts (and the 'NHS family' more generally) that has generated savings through aggregation of purchasing needs and professionalisation of the management of the NHS supply chain. After the Carter Review, NHS Supply Chain became the focal point of the Department of Health and Social Care's Future Operating Model for NHS Procurement (the FOM, which has now become the NOM), 32 which it expects to 'flex the tremendous buying power of the NHS to unlock annual savings of $f^{615}$ million', and with which it seeks to 'make a major contribution to healthcare efficiency'. The transition towards the NOM was foreseen as a staged process. A first stage involved streamlining the existing work of NHS Supply Chain, as well as launching pilot programmes for the centralised acquisition of standard supplies. A second stage would involve the roll-out of a significantly changed supply chain structure managed by NHS Supply Chain (as described in the next section). In April 2016, the NHS PTP resulted in the introduction of the

29 NHS Business Services Authority < www.nhsbsa.nhs.uk>.

30 NHS Supply Chain, 'What We Do' < www.supplychain.nhs.uk/about-us/what-we-do>.

31 See e.g. its website <www.supplychain.nhs.uk>.

32 FOM Handbook (n 26). 
High-Cost Tariff-Excluded Devices (HCTED) programme, a new nationwide system for purchasing high-cost medical devices and implants used in specialised services. ${ }^{33}$ The HCTED system concerns centralised collaborative procurement between NHS Supply Chain and designated NHS trust champions for different device categories. Similarly, in early 2017, a further centralisation programme was launched: the NHS Nationally Contracted Products (NCP) programme, ${ }^{34}$ which is an NHS Supply Chain initiative that aggregates national demand for selected standardised products to purchase them on behalf of the whole of the NHS in order to optimise value and deliver savings. Both programmes served as stepping stones towards the NOM. The HCTED programme will be fully incorporated into the NOM, as part of the new NHS Supply Chain, while the NCP was effectively adopted as an interim measure to establish principles and working practices in advance of the NOM.

The streamlining of NHS Supply Chain activities and the implementation of the NCP were expected to unlock significant savings (c. $f 300 \mathrm{mn}$ ) by October 2018, 35 when the current contract with DHL would have expired and the NOM would be fully operational. It was also expected that the HCTED would see savings of over $f_{60}$ million reinvested into specialist care in its first two years. However, migration into the NOM's second (or fully operational) stage has seen some delays, in particular concerning the award of the NOM logistics contract - which has been the object of a legal challenge by DHL, which opposed the award of the contract to a different operator (Unipart). ${ }^{36}$ In order to bridge the transition in to NOM, the pre-PTP contract with DHL was extended until 28 February 2019. After the High Court dismissed DHL's challenge, ${ }^{37}$ the NOM is now expected to become (fully) operational in March 2019. These delays suggest a more limited (or at least a slower) unlocking of savings than initially anticipated, ${ }^{38}$ and an extended period of implementation of the NOM, or at least some of its aspects. The Department of Health and Social Care, however, remains committed to the NOM.

\section{Centralisation of NHS procurement and supply chain management: the NOM}

Collaborative and centralised procurement strategies have progressively been implemented in the NHS over the last decade or so. ${ }^{39}$ This has resulted in savings through reduced unit costs for standard equipment and supplies, ${ }^{40}$ and reoriented non-pay expenditure by NHS trusts to new channels. NHS procurement expenditure is currently roughly split across three procurement routes: 20 per cent direct expenditure by NHS trusts, 40 per cent expenditure through ad hoc collaborative procurement in NHS hubs, and 40 per cent expenditure through centralised mechanisms managed as 'consolidated

33 NHS England, 'New System for Buying and Supplying High-cost Medical Devices in Specialised Services' <www.england.nhs.uk/commissioning/spec-services/key-docs/medical-devices>.

34 NHS Supply Chain, 'Nationally Contracted Products' <www.supplychain.nhs.uk/savings/nationallycontracted-products $>$.

35 NHS Business Services Authority, 'Strategy 2017-22'

<www.nhsbsa.nhs.uk/sites/default/files/2017-05/nhsbsa-strategy-2017-2022.pdf>.

36 See above (n 3).

37 Ibid.

38 Peter Smith, 'Delays to NHS Future Operating Model Supply Chain Contracts' (Spend Matters UK/Europe, 12 April 2018) <https://spendmatters.com/uk/delays-to-nhs-future-operating-model-supply-chain-contracts>.

39 This is reflective of a broader trend of procurement centralisation across government, which, however, still requires significant improvement. For an early assessment, see NAO, Improving Government Procurement (HC 2012-13 996).

40 See e.g. NHS Supply Chain, ‘ $£ 250$ Million Cash Releasing Savings Achieved for the NHS’ (26 October 2017) <www.supplychain.nhs.uk/news/press-releases/2017/250-million-cash-releasing-savings-achieved>. 
procurement' by NHS Supply Chain. ${ }^{41}$ The PTP strategy is to further centralise procurement in order to leverage the NHS's buying power in the expenditure of the c. $f^{6}$ billion a year in goods and services. This requires a redesign of a new NHS Supply Chain. ${ }^{42}$ The current plan is to progressively migrate towards the NOM, so that by $2023 / 2024$ the proportion of consolidated procurement doubles, from 40 per cent to 80 per cent. ${ }^{43}$ Such a significant increase in consolidated expenditure will in principle reduce the scope for both direct procurement by NHS trusts and for collaborative procurement through NHS hubs, although some hubs have indicated that they will continue to seek collaboration in areas of NHS non-pay expenditure not covered by the NOM. ${ }^{44}$

In a somehow simplified manner, the NOM can be conceptualised as a network of contracts enabling a different work system for the NHS Supply Chain. The NOM comprises 14 separate contracts let to organisations that will manage the service for an initial period of three years (although delays have already been incurred, in particular concerning the logistics contract, as mentioned above), with potential contract extensions based on meeting performance targets. The NOM has been launched on the basis of a commercial arrangement that allows contractors to obtain profit margins in their supplies or provision of services, which is the way in which NHS Supply Chain has been funded until now. Differently, however, the NOM will be centrally funded from 1 April 2019, in what has been described as a 'top slicing', which should facilitate the application of pricing and tariff structures designed through the normal tariff consultation processes run by NHS England and NHS Improvement. However, it is worth stressing that centrally funding the cost of the new system will require further reallocation of NHS funds within the 'NHS family'. In fact, the central funding of the NOM will be drawn from funds currently allocated to NHS trusts, ${ }^{45}$ which will force the latter to use the system (and thus benefit from its expected savings) or else have to find other sources of efficiencies to compensate for their reduced funding. Crucially, if the NOM fails to deliver procurement-related savings commensurate to (at least) the cost of its central funding, the implementation of the system will result in yet one more source of erosion of funding for frontline NHS services - which is the opposite of what it sets out to achieve. Given current delays and foreseeable implementation difficulties, it is not out of the question that the implementation of the NOM will result in a negative financial impact for English NHS trusts, at least in the short run. This comes to put additional pressure on the NOM to deliver financial savings quickly, which may also affect the way some important decisions are made. This can only reaffirm the importance of gaining a better understanding of the checks and balances in the system, and the reviewability of the decisions adopted by NOM-agents, which is the focus of the remainder of this paper.

41 FOM Handbook (n 26) 8.

42 Note that NHS Supply Chain has relabelled the initially described as FOM (future operating model) as the NOM (new operating model). In order to provide updated discussion, the paper refers to the NOM. However, please note that most materials referred to in the footnotes still use the FOM.

43 Department of Health and Social Care, 'Procurement Transformation Programme: Future Operating Model' (December 2016) <www.abhi.org.uk/media/1288/procurement_transformation_programme_brief_fom_ brief_131216-1.pdf>.

44 Presentation given by Keith Rowley, Managing Director, North of England Commercial Procurement Collaborative, at the 'Procurement4Health' 2018 Conference on 12 July 2018.

45 Nick Carding, 'Half a Billion Pounds to be Withheld from Trusts over Two Years' (Health Service Journal, 22 August 2018) <www.hsj.co.uk/ finance-and-efficiency/half-a-billion-pounds-to-be-withheld-from-trusts-overtwo-years/7023189.article>. 
Figure 2: NOM structure

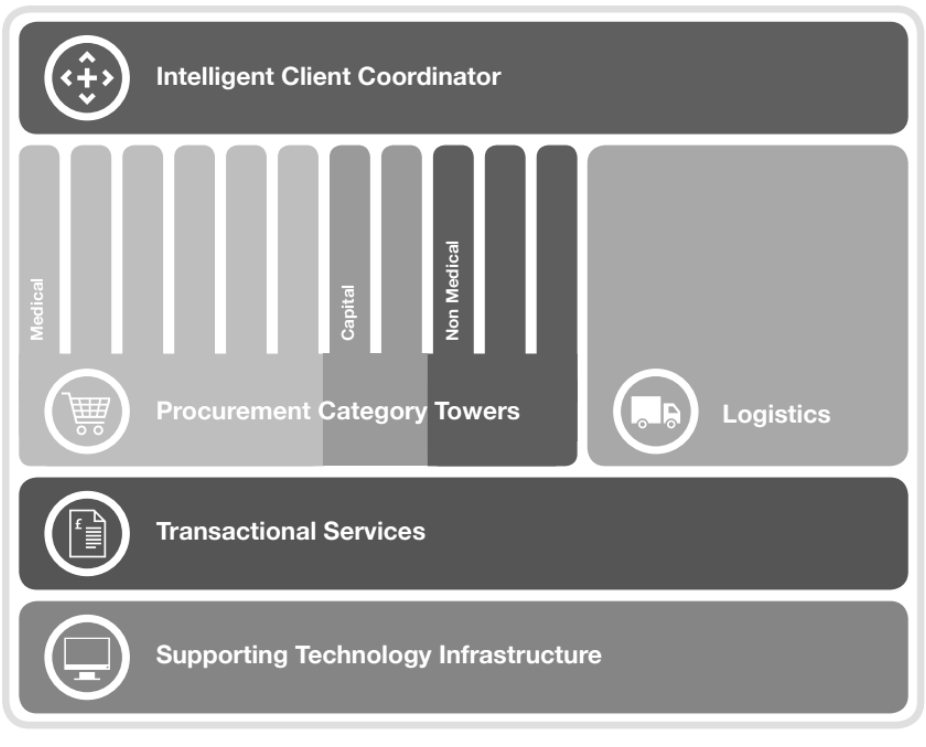

Source: NHS Supply Chain 46

Figure 2 represents the general architecture of the NOM, which adopts a 'tower' structure around cross-cutting horizontal services and vertical procurement 'category towers' for different types of medical, capital and non-medical goods and services.

The NOM thus initially comprised contracts for:

(a) 11 'category tower' service providers (consisting of buying teams focused on specific product categories);

(b) logistics;

(c) transactional services (although these have been finally internalised by the NHS Business Services Authority) $;{ }^{47}$ and

(d) IT services. ${ }^{48}$

Figure 3 identifies the category towers and the providers of those and other services as of the time of writing.

The oversight and operational management of the new NOM contracts and services along with customer engagement activities will be delivered by a new organisation known as the Intelligent Client Coordinator (ICC). The ICC contract has been entrusted to Supply Chain Coordination Ltd (SCCL), a subsidiary company set up by the Department

46 NHS Supply Chain, 'New Operating Model - Frequently Asked Questions' (28 June 2018) <www.supplychain.nhs.uk/icc/ /media/Files/News/NHS\%20SC\%20Customer\%20FAQs\%20280618.ashx>.

47 Presentation given by Chris Holmes, Supply Chain Director, Supply Chain Coordination Ltd, at the 'Procurement4Health' 2018 Conference on 12 July 2018.

48 The extent to which transactional and IT services beyond the NOM's internal needs form part of the tower system is unclear. See e.g. the recent tender of a large value contract by NHS Shared Business Services: 'Salford: Hospital and Related Services' (2018/S 143-327281) <https:// ted.europa.eu/udl?uri=TED:NOTICE:327281-2018:TEXT:EN:HTML\&WT.mc_id=RSSFeed\&WT.rss_f=Other+Services\&WT.rss_a=327281-2018\&WT.rss_ev=a >. 


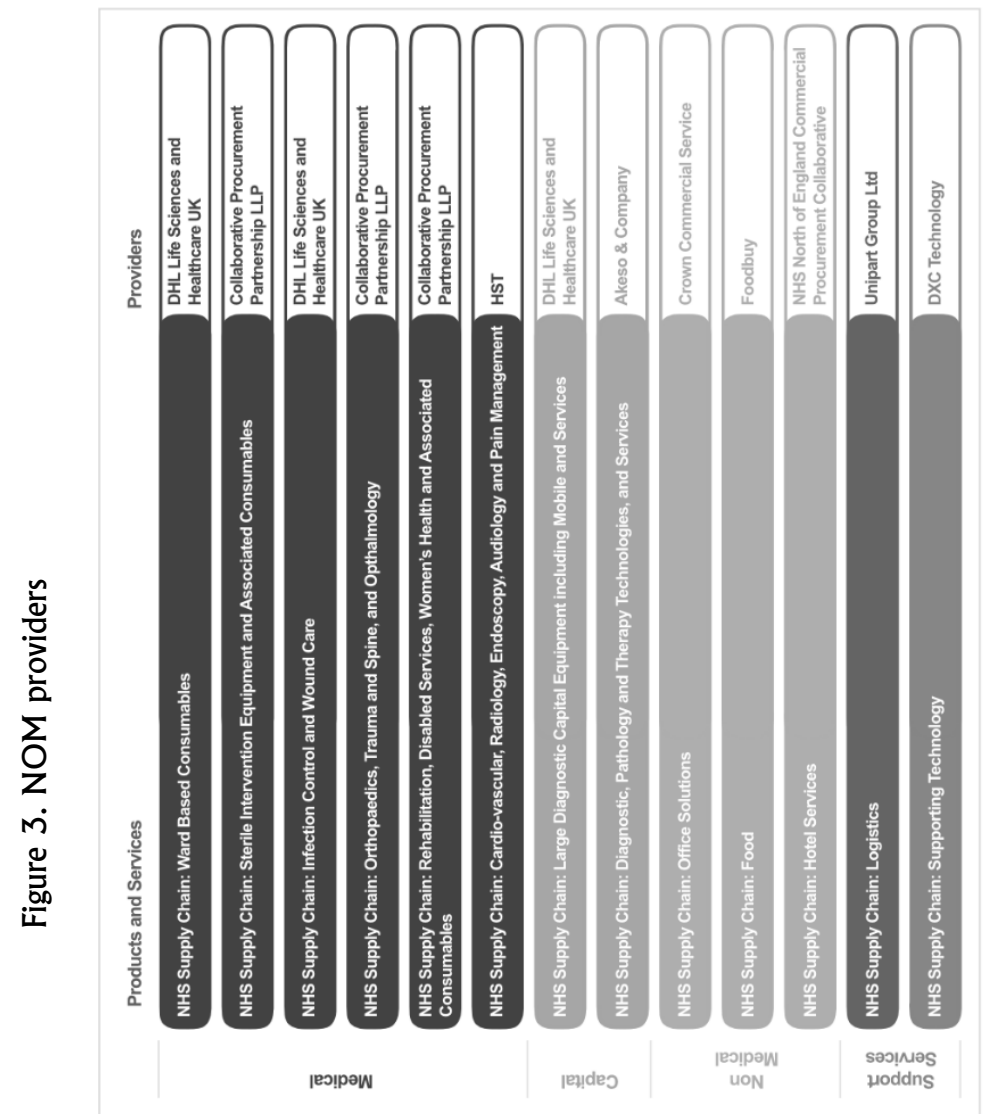

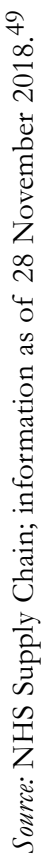

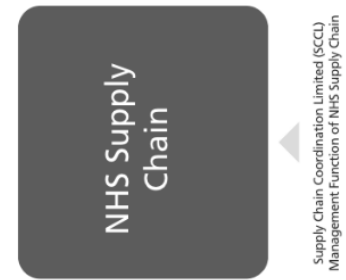

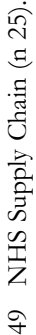


of Health and Social Care and registered in Companies House. However, SCCL is described as a public sector organisation that forms part of the 'NHS family' tasked with rationalising and simplifying the procurement landscape and improving responsiveness to NHS organisations. SCCL is seen as providing a vital role in the clinical and product assurance (CaPA) of the NOM. In that regard, SCCL will help the category tower service providers (the CTSPs) to ensure that, where necessary, products are clinically evaluated. The aim is that all products will go through a product assurance over a 4-5 year rolling period.

\section{THE KEY ROLE GIVEN TO CTSPS}

Functionally, then, the key difference between the current NHS Supply Chain system and the NOM is the significant active role given to the CTSPs in developing category management strategies (that is, the 'go to market approach' at product level). Every CTSP sourcing strategy has to go through the newly created SCCL Category Council for approval. ${ }^{50}$ Once approved by the SCCL Category Council, the CTSPs' category management strategies determine the approach to the procurement of the equipment, consumable and/or services included in the relevant category by practically the entirety of the NHS. Their role is described as comprising 'the clinical evaluation of products and [running] procurement processes on behalf of the NHS. These providers will use category management techniques to create strategies that sustainably provide the NHS with clinically assured products at the best value'. ${ }^{1}$

Under the NOM structure, CTSPs are incentivised to reduce total cost in the system, not just reduce unit prices of the goods and services covered by the relevant category. They hold Guaranteed Maximum Price Target Cost (GMPTC) contracts, under which CTSPs will be paid the operational costs incurred in performing the services against an annual target set out in the contract, but will only make a profit when savings are delivered, on a gainshare basis that is capped. ${ }^{52}$ This is seen as creating adequate incentives for overall cost reduction through system-wide savings - and is probably the justification for the centralised funding of the NOM, which seems based on the premise that those who are bound to benefit from its generated savings (i.e. NHS trusts) should bear the financial cost of the new procurement infrastructure. It is also worth noting that CTSPs will be taking on the operational responsibility of the relevant category tower from the current NHS Supply Chain, and that they are also bound to absorb, where possible, existing procurement team staff from NHS Supply Chain under TUPE. On the whole, then, it seems that NOM is largely a restructuring of the current NHS Supply Chain by means of a spin-off of general tasks to the newly created SCCL and a transfer of branches of activity to NOM contractors through the CTSP contracts, as well as a reallocation of financial risks to NHS trusts (despite the contrary appearance resulting from centralised funding).

50 Apparently, more than 50 category strategies went through the Category Council approval process before the end of July 2018. Presentation given by Jo Gander, CaPA Director, Supply Chain Coordination Ltd, at the 'Procurement4Health' 2018 Conference on 12 July 2018.

51 Department of Health and Social Care, 'Procurement Transformation Programme. Future Operating Model. Frequently Asked Questions for Suppliers' (5 January 2018) <www.supplychain.nhs.uk/Home/News/ /media/Files/News/DH\%20FOM\%20\%20Supplier\%20QA\%2 $0 \% 20$ FINAL.ashx>.

52 The contracts are described as establishing efficiency-generating incentives via key performance indicators (KPIs) and intangible system cost changes, which not only determine the possibility for CTSPs to share in the gains of significant savings, but also the application of performance management measures. Indeed, CTSPs will be withheld payment if they do not achieve $50 \%$ of the relevant KPIs, and will be put on notice of critical service failure if they do not achieve at least $80 \%$ of the relevant KPIs. 
From a governance perspective, crucially, as a result of the NOM structure, CTSPs are not the direct providers of the equipment, consumables or services required under each of the category towers, but rather intermediaries, consultants or advisors (or a hybrid of these functions) that will design and set up additional contractual mechanisms (implicitly, in the form of framework agreements or dynamic purchasing systems, probably underpinned by electronic catalogues) with third parties on bebalf of the NHS. CTSPs then take the place of the current NHS Supply Chain in the provision of centralised purchasing services. However, given that not all CTSPs are part of the 'NHS family' and that their relationship with the new NHS Supply Chain (and in particular SCCL as the ICC) is purely contractual, understanding the exact fit of the CTSP-(user) NHS trust relationship within existing English public law structures will be challenging (as discussed below). Indeed, one of the implicit changes in the move towards the NOM is a potential de facto loss of accountability and reviewability of key decisions in the operation of the NHS supply chain, which is now heavily dependent on the CTSPs. From a functional perspective, it seems that the NOM has created an additional layer of contractualised governance, the effectiveness of which will depend on its interaction with other layers of additional regulation, both upstream (i.e. NHS trust and 'NHS-family' structures) and downstream (procurement and commercial contracts). It has also created an additional layer of potential conflicts of interest that will raise equally peculiar challenges (which are discussed below).

\section{Lights and shadows of the NOM}

It is of course still too early to assess the practical impacts of the NOM and the extent to which it will deliver the expected savings and efficiencies that have been used to justify setting it up - although harbouring doubts about their (timely) materialisation does not seem unjustified. Be that as it may, the NOM's structural and functional design raises important questions. ${ }^{53}$ Some of these questions concern the extent to which the NOM truly generates a different way of working and a more strategic approach than the previous mechanisms for collaborative and centralised NHS procurement. Other questions arise in the context of the subjection of NHS expenditure through the NOM to public procurement and competition law requirements. Before assessing the latter (in the next section), it is worth reflecting on some of the strategic issues. Looking at the list of NOM-contract holders (above, Figure 3), it becomes evident that there are two contractors that accumulate a significant number of contracts: DHL (through DHL Life Sciences and Healthcare UK) and the Collaborative Procurement Partnership LLP (which is made up the four NHS procurement hubs: NHS Commercial Solutions; NHS London Procurement Partnership NHS; East of England NHS Collaborative Procurement Hub; and the North of England Commercial Procurement Collaborative - the latter also holding an additional NOM contract in its own name). It is also worth noting that the largest public sector central purchasing body, the Crown Commercial Service, also holds a NOM contract. This raises two important issues.

First, that the NOM may represent a smaller transition from decentralised towards centralised procurement than it may at first appear. Given that the four pre-existing NHS procurement hubs have partnered together and received major NOM contracts, there may be a displacement rather than a substitution effect between hub-based and NOM-based NHS procurement. In that regard, given that the current level of hub-channelled

53 See e.g. Rob Knott, 'The Future of NHS Procurement? Look into your Procurement Strategy, not a Crystal Ball' (Health Care Supply Association, nd) < https://nhsprocurement.org.uk/the-future-of-nhs-procurementlook-into-your-procurement-strategy $>$. 
procurement is 40 per cent and consolidated procurement managed by NHS Supply Chain is also 40 per cent, the extent to which the 80 per cent of NOM-related procurement that should be achieved by $2023 / 2024$ is significantly different from the current structure raises important questions. To some extent, it would seem that the NOM could result in rather small incremental changes, which may then be insufficient to unlock the very significant reductions in costs that are currently anticipated - and thus result in an undesirable net reduction of funding for frontline NHS services through the NHS trusts' contribution to the central funding of the NOM. Moreover, there is a risk of parallel or competing procurement structures if there is insufficient coordination between NOM and hub-based procurement. For example, recent tenders for enteral feed products and services by individual NHS trusts and regional hubs show that there will be difficulties in migrating over to the NOM system, as these contracts should have been procured under NOM category tower 1 since May 2018. 54

Second, regarding the accumulation of contracts in DHL's hands, a note of caution may be needed in view of very negative recent experiences with other 'strategic suppliers' of outsourced services, such as Carillion ${ }^{55}$ and Capita. ${ }^{56}$ Given the clear strategic risks that result from the accumulation of large volumes of complex and delivery-sensitive services by one (conglomerate) provider, and the ineffectiveness of the government's approach to managing relationships with 'strategic suppliers', 57 the desirability of the NOM strategy may require some additional analysis - in particular from the perspective of systemic risks and resilience and continuity of supply. In a sector where supply disruption can have negative impacts on population health and human lives, this is not a minor concern. Recent examples of failed concentration of risks in NHS suppliers provide evidence of the need for careful analysis of such vulnerabilities of highly concentrated procurement, ${ }^{58}$ which the NOM can only increase exponentially.

Moreover, even if it is not its main driver, it is also clear that the NOM aims to aggregate buying power beyond the 'NHS family' by allowing non-NHS organisations to use the NOM - that is, the NOM would provide procurement and logistics services in the private market, competing with other providers to the public and private sectors, and nonNHS NOM users would be subject to a different pricing model depending on whether they are another public sector organisation or a private company. ${ }^{59}$ This characterises the NOM as a commercially orientated strategy rather than a 'mere' conduit for the selforganisation of the healthcare (public) sector in England. This can have an impact on the way it is run and on the way in which public interest considerations are embedded in NOM-related decision-making and governance. The commercial exploitation of the NOM can also generate additional risks - e.g. concerning the liability of the NOM vis-àvis commercial clients - complex tax issues, and other considerations - e.g. state aid. Moreover, the fact that the NOM is open to non-NHS and private organisations raises important additional issues from both a competition and public procurement law perspective. All of this results in a certainly complex set of legal and governance issues that require some close analysis.

\footnotetext{
54 See e.g. 'United Kingdom-Sheffield: Enteral Feeds' (2018/S 123-279618) <https://ted.europa.eu/TED/notice/udl?uri=TED:NOTICE:279618-2018:TEXT:EN:HTML>.

55 Business, Energy and Industrial Strategy and Work and Pensions Committees (n 2).

$56 \mathrm{NAO}$ (n 2).

57 NAO, Managing Government Suppliers (HC 2013-14 811).

58 Kat Lay, 'Aprons Crisis "Threatens NHS Patients and Staff"” The Times (London, 20 January 2018) $<$ www.thetimes.co.uk/article/chinese-plastic-aprons-crisis-threatens-nhs-patients-and-staff-m6s6pxnss>.

59 FOM Frequently Asked Questions (n 51).
} 
Figure 4: Changes introduced by NOM supply chain compared to direct procurement

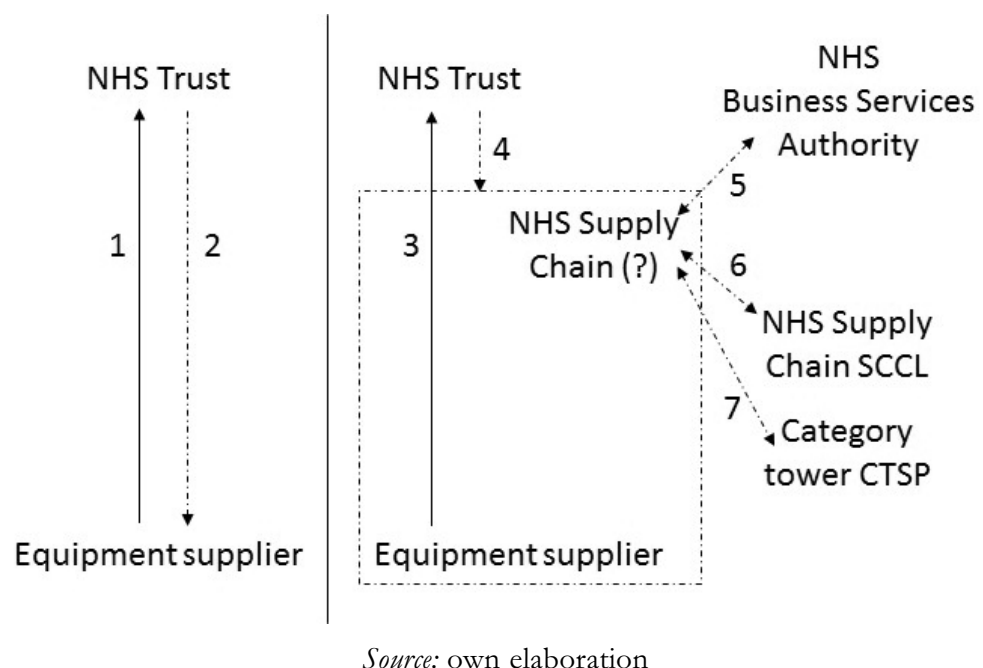

\section{Governance and legal compliance challenges of the NOM}

As mentioned in the previous section, the migration towards the NOM creates an additional layer of contractualised or privatised management of the NHS supply chain that triggers significant governance and legal compliance issues. Figure 4 depicts a comparison of alternative procurement routes for medical equipment that provides a useful framework for the discussion of these issues. It compares the direct procurement and supply of the equipment between the NHS trust and the equipment supplier with a 'NOM' supply.

The direct procurement of medical equipment for its own use by an NHS trust (depicted to the left of Figure 4) creates two relatively straightforward legal relationships. The evident one is a direct contractual relationship with the equipment supplier (1). Underpinning that, the NHS trust would have been obliged to comply with the applicable public procurement rules in the tendering of that contract (2). The first contractual relationship would be subject to its own terms and any disputes would be directly resolved or litigated between the parties (or possibly subjected to alternative dispute resolution mechanisms). Regarding the second legal relationship (procurement), the NHS trust would have been constrained by the Public Contracts Regulations 2015 (PCR2015) ${ }^{60}$ and its decisions would have been open to both the system of procurement-specific remedies and, potentially, to judicial review.

Conversely, the NOM model of procurement (depicted to the right of Figure 4) creates some analytical challenges. In this case, the procurement architecture is much more complex, despite the simplified official account that CTSPs will 'run procurement processes on behalf of the NHS'. This cannot be understood as a simple substitution or intermediation of CTSPs for the benefit of the ultimate 'client' contracting authorities (in the example, the NHS trust). It rather entails a very different approach to the design and execution of procurement operations. Indeed, by tendering a framework agreement on behalf of the NHS under the NOM structure, the CTSP would not hold a straightforward 
direct procurement relationship (or any explicit procurement relationship at all) with the equipment supplier (7). The tendering of the contract would have followed a certain level of scrutiny and authorisation by the NOM ICC, namely the SCCL (6), and the framework agreement would (most likely) have been tendered on the specific behalf of NHS Supply Chain as the relevant contracting authority. However, given that NHS Supply Chain has no separate legal personality, the standard approach under the current (pre-NOM) operation of NHS Supply Chain has been for the latter to act as the agent of NHS Business Services Authority (5), which would be the entity ultimately (indirectly) holding the contract. ${ }^{61}$ Moreover, it is worth noting that the Secretary of State for Health has represented the NHS Business Services Authority in the award of the main NOM contracts to CTSPs, ${ }^{62}$ which can add an additional layer of complication to the procurement of the NOM framework agreements.

The setting-up of a framework agreement under the NHS Supply Chain umbrella would then allow an individual NHS trust to place a call-off for the required medical equipment without the need for any additional public tender (4). ${ }^{63}$ The delivery of the equipment would then be subject to a direct relationship between the equipment supplier and the NHS trust (3), which would, however, be strongly influenced by (and dependent on) the generally applicable clauses of the framework agreement. It would also be possible for the NOM-logistics operator to be involved in part of the implementation of the call-off, although this is more likely for supplies of consumables than for supplies of equipment, in particular if they require installation. In addition to that, the management of this contractual relationship could involve the active participation of the CTSP (or potentially SCCL), as part of the NOM approach to post-sales customer management. While the contract law implications of this solution may be easier to resolve through carefully drafted framework agreements and call-off contracts, the procurement dimension of the NOM creates complications of a different nature. The extent to which compliance with the PCR2015 and the effectiveness of procurement-specific and general judicial review mechanisms can be ensured requires some careful analysis.

Indeed, the rather complicated NOM structure raises important questions and challenges from a governance and legal compliance standpoint. It is submitted that there are four salient issues that require particular attention. First, the classification of the activities of the CTSP on behalf of the 'NHS family' under public law for the purposes of judicial review. Second, the subjection of NOM procurement to the PCR2015 and its implications in terms of procurement compliance not only by CTSPs, but also by NHS trusts. Third, the management of conflicts of interest in this setting. Last, but not least, the applicability of competition law to the NOM structure.

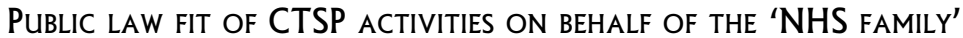

One of the difficulties implicit in the NOM - and, previously, in the management of important aspects of NHS governance and delivery through arms-length organisations and publicly owned commercial entities, such as the NHS Business Services Authority

61 However, it is worth noting that (some of) the NOM contracts with CTSP have been tendered and entered into by the NHS Business Services Authority, represented for procurement purposes by the Secretary of State for Health. This complicates the picture even further, as discussed in the main text.

62 See 'United Kingdom-Newcastle upon Tyne: Procurement Consultancy Services' (2018/S 021-044459) <https://ted.europa.eu/udl?uri=TED:NOTICE:44459-2018:TEXT:EN:HTML>.

63 Please note that, depending on the design of the framework agreement, this could require an additional minicompetition between the potential providers included in the framework agreement. This would raise additional procurement issues. However, in order to keep some simplicity in the discussion, it is assumed that this is a single supplier framework where all call-off conditions are set at the time of award. 
and NHS Supply Chain - is the accountability and reviewability of the decisions of the ever-changing 'NHS family'. If one wants to challenge a given decision, e.g. subjecting it to judicial review, one must first be able to answer complex questions about the attribution to specific authorities or entities of authority and decision-making powers, as well as of the consequences for those decisions. There is a chain of contractual arrangements and directions that are relevant in that regard, which interact with pre-existing legislative and statutory instruments.

The NHS Business Services Authority has been given statutory functions ${ }^{64}$ and issued directions by the Department of Health and Social Care under the National Health Service Act 2006 (most recently in 2016) ${ }^{65}$ in relation to the management of the NHS supply chain. ${ }^{66}$ The Department of Health and Social Care has also concluded a 2014 framework agreement with the NHS Business Services Authority that concerns, amongst other things, the way in which the latter discharges its statutory function by 'managing a 10-year outsourced Master Services Agreement (MSA) for the delivery of supply chain services to the NHS'. ${ }^{67}$ The framework agreement makes it clear that the NHS Business Services Authority acts in accordance with the delegated authority issued to it by the Department of Health and Social Care. Therefore, it seems straightforward to conclude that, in the exercise of its functions concerning the NHS supply chain and, in particular, in the context of the MSA, the NHS Business Services Authority is exercising delegated authority from the Department of Health and Social Care - to which, in turn, the acts of the NHS Business Services Authority are attributable as those of its delegate. The MSA to which the abovementioned delegation refers is the pre-NOM outsourced relationship between NHS Business Services Authority and DHL (i.e. the current NHS Supply Chain), which was revised and extended in 2015. ${ }^{68}$ Under this agreement, DHL (as the outward-facing front of the NHS Supply Chain) acts as the agent of the NHS Business Services Authority ${ }^{69}-$ that is, as the agent of the delegate of the Department of Health and Social Care.

The structure of the NOM suggests that a similar approach may be followed in the future. Contract opportunities that should be covered by category towers have been advertised, e.g. by 'DHL Supply Chain acting on behalf of Supply Chain Coordination Ltd acting on behalf of the NHS Business Services Authority'. ${ }^{70}$ This means that, as a result of $\mathrm{NOM}$ - or along the process of transitioning into NOM - there has been a 'simple' displacement of the NHS Business Services Authority, which is now further removed from the tender of new contracts and framework agreements through the

64 The NHS Business Services Authority (Awdurdod Gwasanaethau Busnes y GIG) (Establishment and Constitution) Order 2005, SI 2005/2414.

65 NHS Business Services Authority (Awdurdod Gwasanaethau Busnes y GIG) Directions 2016 <www.nhsbsa.nhs.uk/sites/default/files/2017-02/Section_2_-_B1_NHSBSA_Directions_2016.pdf>.

66 Ibid Direction 15 and Schedule 4.

67 The latest version was concluded in August 2014. See Framework Agreement between the Department of Health and NHS Business Services Authority <www.nhsbsa.nhs.uk/sites/default/files/2017-02/2014-0808_-_NHSBSA_Framework_Agreement_2014.pdf>.

68 On file with the author.

69 This is made explicit in relevant notices, such as the standard registration notice of the NHS Supply Chain website, which reads 'NHS Supply Chain is operated by DHL Supply Chain Limited (Company Registration No: 528867), as agent for the NHS Business Services Authority' <www.supplychain.nhs.uk>.

70 See 'United Kingdom-London: Disposable Non-chemical Medical Consumables and Haematological Consumables' (2018/S 126-287428) <https://ted.europa.eu/udl?uri=TED:NOTICE:2874282018:TEXT:EN:HTML>. See also 'United Kingdom-London: Continuous Paper for Computer Printers' (2018/S 135-307468) < https://ted.europa.eu/udl?uri=TED:NOTICE:307468-2018:TEXT:EN:HTML>. 
interposition of SCCL (the NOM ICC) as a second-tier agent. This suggests the emergence of a structure where the Department of Health and Social Care, despite holding responsibility for the management of the supply chain of the NHS, is now rather detached from operational decisions, as its own delegate (NHS Business Services Authority) is two steps away from the operational decisions of DHL (as the operating part of NHS Supply Chain, which will progressively be replaced by the CTSPs and/or the new logistics operator, Unipart) acting as the agent of its own agent, the SCCL.

This seems problematic in terms of establishing responsibility along the chain, in particular if one starts from the bottom. It is conceivable that the transparency of the chain of delegation and representation is not always completely clear or visible (in particular concerning decisions not subjected to procurement transparency notices), and third parties may not always have a very detailed understanding of how the different entities within the 'NHS family' relate to each other. Additionally, this structure does not clarify the position of the CTSPs. Publicly available information issued by the Department of Health and Social Care and the strategic design of the NOM make it clear that CTSPs carry out their activities, in particular their procurement activities, on behalf of the NHS. However, the legal structure given to those activities (at least the procurement activities, where CTSPs may not even be mentioned) makes CTSPs practically invisible, inasmuch as they do not tender and enter into the contracts directly in their own name, but acting as second-tier agents of the NHS Business Services Authorities. It thus seems that CTSPs' activities are purely advisory and that the entity formally adopting the decisions is, most likely, NHS Supply Chain or rectius SCCL - which, in both cases, amounts to imputing the decision to the NHS Business Services Authority. This does not seem to represent a situation where CTSPs carry out activities on behalf of the NHS, but rather where the NHS (Business Services Authority) carries out activities designed or shaped by CTSPs. ${ }^{71}$ This can, indeed, liberate CTSPs from a certain degree of responsibility (and liability) for their decisions, as they will rarely be subject to direct challenges by third parties and, most likely, will be solely subjected to and accountable under the specific terms of relevant NOM contracts (which could include alternative dispute resolution mechanisms).

This can make it difficult for interested parties to challenge CTSPs' decisions in judicial review if they assume that, (most of) the CTSPs being private or commercial entities, they are not subjected to the jurisdiction of the administrative courts - as the defendant in judicial review cases is presented as 'the public body/public office which made the decision under challenge'. ${ }^{72}$ Moreover, even if the avenue for judicial review is identified, this structure can still create a disincentive if, in order to challenge CTSPs' decisions, affected parties have to bring an action against the NHS Business Services Authority - which they may not see as directly involved with the decision they wish to challenge. It may also be difficult to access CTSPs' internal documents, as the rules on access to documents and freedom of information may not be easy to apply in this setting.

De facto, the NOM structure, and, in particular, the additional layer of contractualised relationships between CTSPs and the SCCL (acting as NHS Supply Chain's ICC and, ultimately, the agent for the NHS Business Services Authority), results in legal uncertainty. In order to avoid seeing their challenges set aside for procedural reasons, it seems that the NOM structure most likely requires third parties to address their complaints simultaneously

71 This could, for example, make rather challenging the application of precedent concerning the judicial review of decisions adopted by private companies exercising statutory powers. See e.g. $\mathrm{R} v$ Northumbrian Water Ltd, ex p Newcastle and North Tyneside HA [1999] Env LR 715.

72 The Administrative Court Judicial Review Guide 2018 (July 2018) para 2.2.2.1. 
or globally against all entities in the chain (including CTSPs, and possibly all the way up to the Secretary of State for Health) due to the uncertainty that the attribution of decisionmaking powers, authority and legal liability creates. This can hardly be seen as a desirable state of affairs from the perspective of public accountability and judicial review.

\section{SUBJECTION TO AND COMPLIANCE WITH THE PCR2015}

The uncertainty derived from the NOM structure not only affects third parties, but also internal NHS users. Indeed, NHS trusts (and any other contracting authorities within the 'NHS family') have an interest in understanding exactly who holds relevant contractual arrangements under NOM and where do the public/private boundaries lie. NHS trusts qualify as contracting authorities under EU and UK public procurement law and are thus subject to a direct obligation to tender the contracts for acquisitions and supplies above certain value thresholds. One of the advantages of the NOM is that it allows NHS trusts to dispense with those tendering obligations on the basis that acquisitions within the 'NOM system' ensure indirect compliance with the relevant obligations. However, this possibility of indirect compliance is not unqualified.

Under the current rules, a 'user' contracting authority (such as an NHS trust) fulfils its obligations under the PCR2015 when it acquires supplies or services from a 'central purchasing body' (CPB) or using contractual mechanisms concluded by a CPB (reg 37(4) and (5) PCR2015). For these purposes, a 'central purchasing body' means a contracting authority which provides centralised purchasing activities (reg 2(1) PCR2015). This is relevant in two respects. First, where an NHS trust acquires from or through a CPB it does not face independent liability for breach of the procurement rules - unless it directly carries out additional selection activities ('mini-competitions') on top of the more basic (or open-ended) CPB procurement activities (cf reg 37(6) PCR2015). This applies even if the $\mathrm{CPB}$ has not adequately complied with the relevant rules in the tendering of the underlying contracts. The assumption here is that CPBs will comply with the relevant rules and that, where they do not comply, they will be directly exposed to challenges. Second, for this mechanism of indirect compliance to apply, the acquisition needs to be from or through contractual mechanisms established by a CPB that is a contracting authority. 'Contracting authorities' are in turn defined (reg 2(1) PCR2015). In addition to the state, regional and local authorities, this includes 'bodies governed by public law'. The latter are defined as:

bodies that have all of the following characteristics: -

(a) they are established for the specific purpose of meeting needs in the general interest, not having an industrial or commercial character;

(b) they have legal personality; and

(c) they have any of the following characteristics: -

(i) they are financed, for the most part, by the State, regional or local authorities, or by other bodies governed by public law;

(ii) they are subject to management supervision by those authorities or bodies; or

(iii) they have an administrative, managerial or supervisory board, more than half of whose members are appointed by the State, regional or local authorities, or by other bodies governed by public law;

The assessment of whether the NOM architecture complies with these conditions and can, thus, be considered as enabling indirect compliance with the relevant procurement rules under the $\mathrm{CPB}$ regime requires, first and foremost, locating the analysis in a given entity along the NOM chain. If the entities holding NOM contracts and framework 
agreements tendered on behalf of the NHS were the CTSPs themselves or even the SCCL, it would seem clear that this exemption would not be applicable - as they are operating as commercial entities. However, we have seen above that the contracts are tendered by DHL (or, in the immediate future, perhaps the relevant CTSP) 'acting on behalf of Supply Chain Coordination Ltd acting on behalf of the NHS Business Services Authority'. This seems to (legally) allocate the contract to the NHS Business Services Authority. If this is the correct interpretation, then the legality of this mechanism from a procurement perspective mainly derives from the fact that the NHS Business Services Authority was 'established for the specific purpose of meeting needs in the general interest, not having an industrial or commercial character' - as the other two conditions are also clearly met. However, locating the contract under the CTSPs, or even under SCCL (as the formal legal entity seemingly backing the NHS Supply Chain, in particular after the expiry of the service management agreement with DHL) would raise questions as to the fit of the NOM architecture under the CPB-based exemption from direct compliance with the procurement rules. More importantly, given that the NOM architecture is open to commercial exploitation for the benefit of non-NHS and even private organisations, the 'non-commercial' nature of the NOM system may be open to future challenges (as well as triggering competition law concerns, see below).

It seems that there is a converging interest in (legally) locating all NOM contracts under the legal personality of the NHS Business Services Authority - despite the fact that the latter seems to have made great efforts to distance itself from the direct management of the NOM, most recently through the creation of SCCL. However, for this not to limit third-party rights and interests and to avoid generating risks of non-compliance with the applicable procurement rules, it seems necessary that: (i) any and all acts and decisions involved in the operation of the NOM - including those of private entities and, in particular, CTSPs - are attributable to the NHS Business Services Authority for the purposes of legal challenge and judicial review (as discussed above); and (ii) that the commercial exploitation of the NOM for the benefit of non-NHS and even private organisations is either significantly constrained or, preferably, completely excluded. This would, in practice, resolve some of the issues discussed so far through the simple (legal fiction and) solution of assigning all 'NOM activity' to the NHS Business Services Authority for the purposes of accountability, reviewability and legal compliance. However, even if these two issues are galvanised in the operation, governance and accountability of the NOM, there would still be additional challenges in ensuring adequate legal compliance with other aspects of procurement and competition law.

\section{PARTICULAR CHALLENGES IN THE MANAGEMENT OF CONFLICTS OF INTEREST}

A challenge that may seem difficult to resolve concerns the identification, prevention and management of conflicts of interest within NOM. One of the innovations of the PCR2015 was the transposition into the UK system ${ }^{73}$ of new EU requirements for the prevention of conflicts of interest. Regulation 24 PCR2015 is clear in demanding that contracting authorities 'take appropriate measures to effectively prevent, identify and remedy conflicts of interest arising in the conduct of procurement procedures so as to avoid any distortion of competition and to ensure equal treatment of all economic operators'. In the context of NOM, given that contracts are being advertised as tendered by the DHL (or the CTSP in the future) 'acting on behalf of Supply Chain Coordination

73 For general discussion, see Albert Sanchez-Graells, 'The Implementation of Directive 2014/24/EU in the UK', in Steen Treumer and Mario Comba (eds), Modernising Public Procurement: The Approach of Member States, vol 8 European Procurement Law Series (Edward Elgar 2018) 278-307. 
Ltd acting on behalf of the NHS Business Services Authority', this requires measures to ensure that the CTSPs are within the scope of this rule. Given that CTSPs will be the ones establishing procurement strategy and, most likely, drafting procurement documents, a narrow interpretation of the scope of application of the rules on conflict of interest as only applicable to the formal contracting authority (the NHS Business Services Authority) would be undesirable - and possibly subject to challenge. ${ }^{74}$ CTSPs must thus be under a strict obligation to take measures to prevent, identify and remedy conflicts of interest.

In a mirror image, reg 57(8)(e) PCR2015 allows the contracting authority to exclude economic operators 'where a conflict of interest within the meaning of regulation 24 cannot be effectively remedied by other, less intrusive, measures'. This provision is intended as a residual clause whereby situations where the contracting authority cannot take internal measures to resolve a conflict of interest (e.g. the substitution of individual members of the evaluation team affected by a conflict of interest) can be resolved through the exclusion of the economic operator concerned. This seems more difficult to interpret where the conflict of interest is not between the contracting authority (the NHS Business Services Authority) and the potential provider, but rather between the CTSP and the potential provider (e.g. if they have common business interests), as the contracting authority cannot take effective internal measures.

The peculiarities of the potential conflicts of interest in the context of NOM suggest that there is a need for careful analysis and, potentially, for explicit guidance to be adopted. Given the existence of rather detailed NHS England statutory guidance on managing conflicts of interest for clinical commissioning groups, ${ }^{75}$ that would seem like a good starting point.

\section{ApPLICABILITY OF COMPETITION LAW TO NHS SUPPLy ChAIN AND THE NOM}

Another difficulty arising from the structure of the NOM concerns the assessment of the extent to which the activities of the different operators are subjected to competition law scrutiny - which is a rather fundamental check and balance for market-based governance mechanisms. An exhaustive analysis of this issue would exceed the possibilities of this paper. However, there are two salient issues that require particular attention. First, the extent to which competition law is applicable to the NOM as a sui generis CPB. Second, whether the NOM structure creates risks of violation of competition law standards, in particular concerning the exchange of competition-sensitive information.

The first issue is important because the NOM, by aggregating and exercising public buying power, seems particularly prone to potential claims of anticompetitive behaviour - and, in particular, of exclusionary and/or abusive behaviour against the interests of (potential) NHS suppliers. In that regard, the received wisdom is that entities that are engaged in procurement activities are shielded from the application of competition law, unless they also engage in downstream competitive markets. Or, in other words, that competition law does not apply to the procurement activity in itself. This is the result of case law of the Court of Justice of the European Union (CJEU) ${ }^{76}$ that reversed the previous domestic position of the UK Competition Appeal Tribunal (CAT) that

74 Indeed, the concept of conflict of interest needs to be given an expansive interpretation. See Counted4 Community Interest Company v Sunderland City Council [2015] EWHC 3898 (TCC).

75 NHS England, 'Managing Conflicts of Interest: Revised Statutory Guidance for CCGs 2017’ (16 June 2017) $<$ www.england.nhs.uk/publication/managing-conflicts-of-interest-revised-statutory-guidance-for-ccgs$2017>$.

76 Judgment of 11 July 2006, FENIN v Commission, C-205/03 P, EU:C:2006:453. Albert Sanchez-Graells, Public Procurement and the EU Competition Rules (2nd edn, Hart 2015) 156-71. 
competition law and its prohibitions applied to any entities which behaviour generated the effects that competition law sought to prevent, including in the context of their procurement activities. ${ }^{77}$

This could be seen as an exemption from the competition law prohibitions for the procurement activities covered by the NOM. However, it is worth noting that the CJEU case law did not exclude the possibility of applying competition law to entities that engage in procurement as an economic activity. ${ }^{78}$ In that regard, the applicability of the prohibitions in the Competition Act 1998 (CA1998) $^{79}$ and Articles 101 and 102 of the Treaty on the Functioning of the EU (TFEU) to the NOM is not out of the question. To the contrary, it is submitted that the NOM and, in particular, NHS Supply Chain (as a front entity jointly run by the relevant CTSP, SCCL and the NHS Business Services Authority) is subject to competition law. Indeed, to the extent that the NOM is premised on the existence of commercial activity (both in the generation of savings and their split between the CTSPs and the NHS Business Services Authority) and is not a 'closedsystem', but rather susceptible to commercial exploitation through the participation of non-NHS and private organisations, by design, it represents the carrying out of an economic activity that triggers the applicability of competition law.

Independently from the above, and even if the NOM was not seen as itself subject to competition law, the second issue it raises from a competition law perspective concerns a risk of potential illegal exchanges of information in violation of the prohibition in Chapter I CA1998 and Article 101 TFEU - or, at the very least, a heightened risk of collusion in NHS procurement markets. The need to ensure confidentiality of purchasing prices has been a primary concern of the NHS Business Services Authority's Scorpio Price Benchmarking project, ${ }^{80}$ which pledged to its participants to keep information confidential and to not share it with NHS Supply Chain. Indeed, the need to keep price information confidential and to prevent its dissemination in the market is aligned with competition law requirements, which oppose competitors' access to commercially sensitive information. However, the extent to which sensitive price information will be used in a competition law-compliant manner under NOM raises some questions. Indeed, one of the mechanisms underpinning the NOM is the development and further use of the purchase price index and benchmarking tool, as well as other price-monitoring tools required to set baseline prices and assess the generation of savings (especially by CTSPs). In that regard, the creation of databases of prices should be accompanied by adequate competition safeguards.

Amongst others, these issues seem relevant enough for the Competition and Markets Authority (CMA) to take an interest in any complaint concerning the functioning of the NOM and for it to keep a close eye on the potential emergence of competition problems.

77 BetterCare Group Ltd v Director General of Fair Trading [2002] CAT 7. For discussion, see Sanchez-Graells (n 76) 159.

78 Albert Sanchez-Graells and Ignacio Herrera Anchustegui, 'Impact of Public Procurement Aggregation on Competition: Risks, Rationale and Justification for the Rules in Directive 2014/24', in Rafael Fernández Acevedo and Patricia Valcárcel Fernández (eds), Centralización de compras públicas (Civitas 2016) 129; and Albert Sanchez-Graells and Ignacio Herrera Anchustegui, 'Revisiting the Concept of Undertaking from a Public Procurement Law Perspective - A Discussion on EasyPay and Finance Engineering' (2016) 37(3) European Competition Law Review 93.

79 SI 1998/41.

80 On file with the author. 
Even if NHS Improvement is co-competent for the enforcement of competition law, ${ }^{81}$ given the proximity of entities within the 'NHS family' and the strategic interests of the Department of Health and Social Care in the NOM, this seems a clear case where independent CMA involvement could generate better outcomes than a softer (self)regulatory approach by NHS Improvement.

\section{Conclusion}

This paper has explored the fit of the NOM within the broader context of efficiencydriven NHS re-regulation, and its potential to unlock funds to support the delivery of current aspirations for the transformation of the NHS through STPs. It has explored the legal and business structure of the NOM and assessed the strategic, governance and legal compliance challenges it presents. The paper has suggested that, in order to address such challenges, it is necessary to functionally disregard the multiple layers of contractualised management of the NHS supply chain and proceed to effectively locate all relevant NOM relationships, including those resulting from CTSP activity, under the NHS Business Services Authority for the purposes of their judicial review and their subjection to procurement law. The paper has also identified the need for explicit guidance on the management of conflicts of interest with the NOM and for independent oversight by the CMA of the potential anticompetitive effects of the exercise of buying power on which the NOM rests, as well as of the potentially excessive exchange of commercially sensitive information. Only if these checks and balances are made effective will the operation of the NOM be subjected to effective oversight.

81 See the memorandum of understanding between the Competition and Markets Authority and NHS Improvement (1 April 2016) <https://improvement.nhs.uk/documents/29/NHS_Improvement_and_ CMA_MoU_-_010416.pdf>. For discussion, see A Sanchez-Graells, 'Monitor and the Competition and Markets Authority' (University of Leicester School of Law Research Papers No 14 2014) <https://lra.le.ac.uk/handle/2381/29333>. 
